\title{
PLANEJAMENTO DE CAMPANHA DESENVOLVIDO A PARTIR DO UNIVERSO ASTROLÓGICO PARA O MUNDO DA MODA
}

\section{CAMPAIGN PLANNING DEVELOPED FROM THE ASTROLOGICAL UNIVERSE FOR THE FASHION WORLD}

\author{
VICTÓRIA BALADY1 \\ PEDRO HENRIQUE SILVA SALES ${ }^{2}$ \\ THAMIRES CRISTINA LOPES DE CARVALHO FIRMINO³
}

\section{RESUMO}

O presente trabalho tem a finalidade de criar um planejamento de campanha desenvolvido a partir do universo astrológico para o mundo da moda diante de cada signo. O projeto consiste em elaborar e mostrar a relevância que o mundo astrológico tem para as pessoas e o quanto isso influencia na compra final. Com o objetivo de detalhar cada comportamento diante ao signo, objetivou-se em deixar a visão de mercado astrológico mais clara aos seus consumidores, além de mostrar maneiras de potencializar a força que cada signo tem para consumidor. Em todo o planejamento, o processo consistiu em mostrar o mundo astrológico já presente nas peças com cores e temáticas de tendência, e, por fim, utilizar o mundo da moda como forma de abordagem de público.

Palavras-chaves: planejamento de campanha - astrologia - moda - universo astrológico.

\footnotetext{
${ }^{1}$ Mestre em Planejamento e Desenvolvimento Regional pela Universidade de Taubaté, com pós graduação Gestão em Recursos Humanos pela Universidade Salesianas de Lorena e graduação em Direito pela Universidade Salesiana de Lorena (1998). Atualmente é docente do Centro Universitário Santa Teresa D’Ávila nas áreas de Administração, Publicidade e Propaganda e Pós Graduação Lato Sensu em Marketing Empresarial, e também atua no SENAC - Serviço Nacional de Aprendizagem Comercial nas áreas de Administração, Empreendedorismo e Aprendizagem. Tem experiência na área de Administração, com ênfase em Marketing e Projetos para Pequenas e Médias Empresas, mediando principalmente nos seguintes temas: estratégia de mercado, marketing, liderança e gestão de pessoas.

2 Possui graduação em Comunicação Social - Publicidade e Propaganda pelo Centro Universitário Teresa D`Ávila.

3 Possui graduação em Comunicação Social - Publicidade e Propaganda pelo Centro Universitário Teresa D`Ávila.
} 


\section{ABSTRACT}

The present work aims at the planning of a campaign developed from the astrological universe to the world of fashion before each sign. The same is to show and show the relevance of the astrological world to people and how much it influences the final purchase. In order to know each of the instructions at its side, it aims to leave a clearer astrological market view to its consumers, as well as show the potentialities of a strength that each sign has for the consumer. Throughout the process, the process consisted in showing the astrological world already present in the pieces with nuclei and trend themes, and, finally, using the fashion world as a way of approaching the public.

Keywords: campaign planning - astrology - fashion - astrological universe

\section{INTRODUÇÃO}

Trata-se de um planejamento de campanha voltado para o universo astrológico, que vem ganhando forte relevância no momento atual, tornando-se uma referência na sociedade. $\mathrm{O}$ trabalho irá abordar todo o desenvolvimento de uma campanha para o mundo da moda baseando-se na astrologia e segmentando-o de maneira única e alinhada com os seus propósitos.

O segmento da moda é um mercado que está em constante mudança e recriando-se a toda instante, independe de seu lugar, época, cultura, idade, etc. O vestuário sempre foi uma das principais maneiras de se expressar para o mundo, sem ao menos dizer uma palavra, sendo muitas vezes o principal cartão de visita. Através do vestuário é possível visualizar nichos de qual cada ser humano se encaixa ou pretende se encaixar.

No atual momento de mercado, a astrologia entra como uma ferramenta para auxiliar a forma de como se planejar de maneira mais alinhada com o próprio universo e transformar isso ao seu favor, trazendo seus princípios tanto no desenvolvimento do planejamento até a campanha em si, ajudando-a a ressaltar sua identidade e características de cada um dos doze signos nas peças fashions.

Tendo em vista essa necessidade do ser humano de não ser apenas visto, mas compreendido pela imagem que se é apresentada, é primordial acompanhar as mudanças que ocorrem à todo vapor no setor da moda e com isso adequar-se a 
astrologia. Segundo Caldas (2004), a adopção de uma determinada definição de tendência é assumida como sendo uma verdade ligada a uma visão de futuro. Para que se criem tendências há uma necessidade de criatividade, pois a criatividade contempla a capacidade de gerar novas variantes.

\section{DESENVOLVIMENTO DO PLANEJAMENTO DE UMA CAMPANHA}

\subsection{Importância dos 4 P's}

É de suma importância primeiramente compreender o conceito de marketing e a sua função de colaboração na venda de produtos até chegar ao seu consumidor, antes de atingir definitivamente os 4P'S e compreendê-los.

Marketing deriva da palavra Market, que sendo traduzida como mercado significa "to marketing", que vem do verbo comercializar. O sufixo 'ing' é usado para representar uma ação que está acontecendo agora e forma então a ação de comercializar agora. É uma necessidade para que determinada instituição alcance o resultado esperado.

Segundo Gérad (1973, p.10)

É um estado de espirito impregnado de objetividade, aberto à pesquisa, em perpétua busca da verdade, exatidão e novidade, que considera suspeito, como dogma falacioso, tudo quanto hoje é considerado certo. Contudo, o Marketing exige que se pese tudo, também exige não haver hesitações. É orientado para resultado e se concentra na decisão (GÉRAD, 1973, p.10).

Tendo em vista que essa ferramenta é importante para vendas, o marketing tornou-se uma obrigação para todos que pretendem atingir e seguir no mercado atual. Marketing é um processo social por meio do quais pessoas e grupos, obtém aquilo de que necessitam e desejam por meio da criação, oferta e troca de produtos e serviços tendo como retorno recursos financeiros e de bens tangíveis ou não.

Para que o marketing tenha o sucesso esperado, é preciso primeiro identificar e entender os elementos para desenvolver cada uma das ações em questão. Os 4P's são uma das ferramentas mais utilizadas para fidelizar o alcance de vendas de uma forma mais abrangente e significativa.

Os 4P's também conhecidos como Mix de marketing ou Composto de marketing, foram definidos por Kotler (1998, p. 97) como "o conjunto de ferramentas 
que a empresa usa para atingir seus objetivos de marketing no mercado-alvo.". Tratase de um conjunto de ferramentas que implicam diretamente nas vendas de bens colaborando e dinamizando a distribuição em maior quantia na sua prestação de serviços.

Vale entender o significado dessa formula tão importante para organizações. Os 4P'S, produto, preço, praça e promoção, possibilita o desenvolvimento de uma estratégia tornando-a mais competitiva e influenciando o comercio de forma direta até chegar em seu consumidor final. Os quatro elementos dessa estratégia, torna esse artificio em ações mais bem executadas e planejadas com direcionamento correto para o público-alvo em questão.

É de suma importância entender todo esse processo passo-a-passo e o significado de cada uma das ferramentas e o tamanho da sua importância para empresas.

\subsubsection{Produto}

Para Kotler e Armstrong (2007) produto é "algo que pode ser oferecido a um mercado para apreciação, aquisição, uso ou consumo e para satisfazer um desejo ou uma necessidade". O Produto deve obrigatoriamente ser um desejo para seu cliente. Suprindo as expectativas de forma que o mesmo tenha qualidade, design afável, e serviços de qualidade.

Para a elaboração de um bom produto, vários fatores são levados em consideração, os autores definem três níveis pilares de produto para eficiência de sua elaboração. O primeiro é o produto núcleo onde é o beneficio central, caracteriza a essência funcional do produto; o segundo se trata do produto básico que contém como diretriz os fatores embalagem, nome da marca, nível de qualidade, design e características específicas do produto e o terceiro nível que implica nos serviços que envolvem a aquisição do produto como, instalação, serviço de pós-compra, garantia de entrega e crédito. Suprindo as expectativas que o próprio cliente gera em torno do produto.

\subsubsection{Preço}

O preço deve ser tratado de forma justa, com concessões, descontos e prazo de pagamentos agradem e fidelizem o consumidor. Las Casas (2006) descreve que 
"o preço ajuda a dar valor às coisas e representa uma troca pelo esforço feito pela empresa vendedora através da alocação de recursos, capital e mão-de-obra dos produtos comercializados".

O foco nunca será a quantia que o consumidor gastará com o produto, mas sim o valor agregado que ele obtém ao adquirir o produto. Para Kotler e Keller (2006) o preço é o único elemento do mix de marketing que gera receita, os demais produzem custos, também é um dos elementos mais flexíveis, pois ele pode ser alterado com rapidez.

\title{
2.1.3. Promoção
}

Promoção é o conjunto de ações que estarão incidindo sobre certo produto, de forma a estimular a sua comercialização ou divulgação. A promoção é um dos pontos mais importantes na prestação de serviços. Churchill e Peter (2000) argumentam que promoção de vendas é uma pressão de marketing feita dentro e fora da mídia, aplicada em um período de curto prazo para o consumidor, varejista ou atacadista, com o objetivo de estimular e aumentar a demanda ou a venda de um produto.

Desse modo, trata-se como o produto será visto e exposto para vendas para de cliente. A força de vendas pessoal, relação públicas, promoção de vedas, marketing e merchandising é as formas de como esse serviço será vista.

\subsubsection{Praça}

A ferramenta praça são os canais de vendas, cobertura e variedade que o produto oferece. É também uma organização de seus estoques, como será transportado e seu visual na promoção de vendas.

\begin{abstract}
Um bom produto e um preço adequado não são suficientes para assegurar vendas. É necessária também a existência de uma forma eficiente de conduzir os produtos até os compradores finais. Caso contrário, o plano de marketing será deficiente, pois os consumidores estão acostumados e muitas vezes exigem comprar seus produtos em locais que lhe sejam acessíveis, convenientes e disponíveis quando necessitarem (LAS CASAS, 2006).
\end{abstract}

\subsection{Estratégias de campanhas}

A estratégia de campanha é uma etapa importante para atingir os objetivos na comunicação de uma organização. Desse modo, cada tipo de campanha possui as 
suas especificidades e características vinculando diretamente as estratégias de posicionamento do plano de marketing,

As decisões a serem tomadas são totalmente relevantes e importantes para o início de ações publicitarias e levam em conta quais meios de comunicação serão utilizados, quais propostas e produtos que serão distribuídos e ou divulgados e como será visualmente escolhida. Desse modo a empresa ganha posicionamento antes de iniciar as ações de marketing como forma de dar direcionamento e rumo à marca.

Segundo Kotler (2006, p. 305), a palavra posicionamento tornou-se conhecida devido a dois executivos da área de propaganda, Al Ries e Jack Trout, que afirmavam que, "posicionamento não é o que você faz com o produto. Posicionamento é o que você faz na mente do cliente em perspectiva, ou seja, você posiciona o produto na mente do cliente em potencial".

As estratégias de uma campanha podem variar conforme o foco de uma organização, ou seja, que tipo de publico e quais informações serão relevantes.

\subsection{Tipos de campanha}

- Campanhas, informativas: são os benefícios e vantagens que a marca tem a oferecer;

- Campanhas de testemunho: é utilizada para provar um fato garantindo o testemunho de alguém;

- Campanha de comparação: comparação de dois produtos a fim de evitar denegrir a imagem da concorrência de modo que a mesma não se sinta ofendida;

- Campanha de Humor: objetiva retratar um momento de humor geralmente vindo em forma sátira como campanha mais adequada;

- Campanha Ofensiva: pretende-se mostrar o lado frágil da concorrência;

- Campanha de Defesa: aproveitamento e potencialidades organizacionais;

- Campanha indiferenciada ou institucional: foca em mostrar o que a marca tem a oferecer, ou seja, o lado institucional de uma organização não priorizando ou mostrando as vendas, mas sim a empresa em foco;

- Campanha de Reposicionamento ou posicionamento: tem como objetivo principal ganhar destaque na mente dos consumidores. É uma forma de fidelização de clientela. 


\subsubsection{Campanha de oportunidade}

Uma das estratégias publicitárias que gera repercussão. São aqueles anúncios boca, boca e/ou comerciais que surgem de fatos que virou notícia e que já aconteceram. Isso pode servir de inspiração e ser uma grande oportunidade de promover empresas. Esses anúncios são chamados de Campanhas de Oportunidade cujo sua característica principal é gerar repercussão com acontecimentos, datas comemorativas e até mesmo notícias que tiveram e ganharam uma grande repercussão.

Aproveitando desse contexto, as campanhas de oportunidade tendem a ter o conhecimento do seu público alvo, para que caso contrário, o anuncio corre sérios riscos de perder significado e não ser compreendido pelos seus clientes. É de suma importância entender esse tipo de campanha da qual aproveita dos temas relevantes do mundo e que tem como objetivo mostrar atributos de seus produtos de uma forma interessante.

\subsubsection{Campanha de lançamento e sustentação}

A campanha de qualquer peça publicitaria deve conter um contexto que se encaixe com a mensagem a ser passada para o público em especifico. Sabe-se que campanhas buscam atingir um público utilizando cores, imagens e temática que dão sentido na comunicação para que o receptor da mensagem consiga entender e compreender o que foi transmitido pelo anunciante.

A campanha de lançamento faz parte de um viés importante para as organizações. Ela elabora um apelo pelo novo, isto é, ela busca mostrar um lançamento junto à novidade de algo que está surgindo no mercado com uma linguagem informativa e coesa para fácil entendimento do público a ser atingido. A campanha de lançamento tem como enfoque transmitir a originalidade para seu público com uma temática agradável e legível.

As campanhas de sustentação partem de um princípio de maturação de produtos, ou seja, ela busca manter-se após o lançamento do seu produto sustentando os 4P's do marketing e não dando espaço para o concorrente. Dessa forma esse tipo de ferramenta fixa-se na consciência do consumidor que o produto existe e que o mesmo é confiável. 


\subsubsection{Campanhas promocionais}

Campanhas promocionais são aquelas que apresentam algum tipo de oferta vantajosa e especial com o propósito de agregar valores ao seu produto, aumentar o interesse de clientes e influenciar a compra de bens na função de diferenciar seus serviços do concorrente. Também tem como cerne, reduzir o estoque de lançar novos produtos dando progressividade no aumento de vendas.

As campanhas de promoção, ou campanhas promocionais, surgem de estratégias que ajudam e motivam ainda mais vendedores como forma de oferecer uma opção mais satisfatória na abordagem de vendas para seus clientes.

Lupetti (2000) afirma que quando uma outra organização desenvolve uma campanha promocional, terá como objetivo a evidencia de sua marca. Para que o fato não se concretize, a concorrência deverá estar atenta para antever a ação e agir de modo a apresentar uma outra campanha promocional, focando o mesmo tipo de campanha e o mesmo período de lançamento. Assim, ambas as empresas terão o aumento em vendas, porém não obterão a marca evidenciada.

\section{ASTROLOGIA}

\subsection{Conceito de astrologia}

A astrologia é existente há milênios, nas suas diversas maneiras, por todas as sociedades do planeta. Desde os mais remotos grupos humanos que se obtém notícia, até civilização planetária atual, passando por todas as culturas, desde ocidentais até os orientais, não houve sequer uma época em que o homem não olhasse para o céu, buscando uma compreensão maior do mundo ao seu redor ou, pelo menos, uma orientação para o seu dia. Para isso, com base nas observações dos ciclos da natureza, o homem estabeleceu relógios, calendários e o sistema astrológico.

Apesar de se obter uma vasta diversidade das técnicas e práticas, é possível afirmar que o objetivo fundamental de qualquer astrologia é que há uma relação entre determinado evento celeste, concebido do ponto de vista geocêntrico, e certos eventos terrestres. Segundo Lynn Thorndike (1995, p.273-278), o sistema astrológico foi considerado lei universal da natureza, até Newton, tratando-se de um saber coeso, cuja finalidade serie entender os acontecimentos na Terra, por meio da relação de certos fenômenos regulares e previsíveis que ocorrem no céu. 
Tendo em vista isso, a capacidade da astrologia não só é algo plausível, o que não significa que o nosso destino está escrito nas estrelas. Segundo Plotino, "O movimento dos astros indicam os eventos futuros, e não os produz, como se crê frequentemente" (PLOTINO, 1966, II-3-1). Logo essa definição dos astros, não teria um caráter determinante tão forte, do tipo causa-efeito, como se pode pensar, e sim denotativo, algo a ser decifrado, pensado, traduzido, interpretado. Assim, é possível pensar no Mapa Astrológico como um índice, um sistema de referências ou uma diretriz para a construção de um discurso dado a partir de um evento em questão, seja o nascimento de alguém, a abertura de uma empresa ou um planejamento.

\subsection{A astrologia representada através da moda}

Moda vem do latim modus, cujo significado é modo. Moda, segundo Palomino (2002), é muito mais do que roupa, é um sistema que integra o simples uso das roupas do dia-a-dia a um contexto maior, político, social, sociológico.

O fato é que, em português, a palavra adquiriu o seguinte sentido:

moda, s. f. (fr. mode). 1. Uso corrente. 2. Forma atual do vestuário. 3. Fantasia, gosto ou maneira como cada um faz as coisas. 4. Cantiga, ária, modinha. 5. Estat. O valor mais frequente numa série de observações. 6 . Sociol. Ações contínuas de pouca duração que ocorrem na forma de certos elementos culturais (indumentária, habilitação, fala, recreação etc.). S. f. PI. Artigos de vestuário para senhoras e crianças. Antôn.: anti-moda (DICIONÁRIO BRASILEIRO DA LÍNGUA PORTUGUESA, 1980, p.1156)

A moda, atualmente, vive seu apogeu em uma sociedade dominada pela efemeridade, sendo o símbolo máximo da renovação e da ânsia de consumo de novos produtos.

As roupas dançam nos cabides e depois envolvem os corpos humanos num balé que aproxima, afasta e recria todos os dias para embalar nosso modo de vida em direção ao futuro (GARCIA; MIRANDA, 2005, p. 14)

Uma tendência geralmente é lançada, pela elite do mundo fashion. Mas, muitas vezes, a tendência também pode se manifestar de forma hierárquica contrária à mania.

Um exemplo dessa situação é a moda se utilizando da astrologia. Nesse caso, a tendência é ditada pela população e legitimada pela elite da moda. A partir de então, 
ela será consumida pela classe média, a qual espera que a novidade seja adotada por grandes marcas para usá-la exibindo etiquetas de grifes.

Com isso, a partir da tendência propriamente ditada, os conceitos da astrologia serão representados nos vestuários, para que gere uma identificação com o próprio consumidor, onde ele se sinta único com suas características representadas.

Susan Miller, famosa astróloga, explica que:

[...] segundo a astrologia, os planetas que regem cada signo são responsáveis por diferentes características da personalidade. Desta forma, quando as cores referentes a cada planeta são levadas para o look, essas qualidades também são potencializadas (MILLER, 2012).

\subsection{A astrologia no planejamento de campanha}

No mundo dos negócios levamos em consideração diversos fatores, como orçamento, disponibilidade de tempo, decisão dos diretores, clientes e dependendo, até dos fornecedores, por exemplo. Mas, podemos levar em consideração outro aspecto se quisermos saber se o que desejamos iniciar ou programar pode dar bons frutos e atingir as metas estabelecidas. A Astrologia tem o tempo como aliado e é possível escolher os melhores momentos para iniciar projetos de acordo com os objetivos do planejamento.

Para Cintia Padro, dona do blog Astrologia e leitura de Aura, por exemplo, se a pessoa tem como meta inaugurar uma loja e a finalidade é ter muitos clientes, o melhor é abrir as portas em uma Lua Cheia, pois certamente irá atrair muitas pessoas. Se o negócio for uma padaria ou restaurante, o bom é que a Lua esteja em Câncer ou Touro, que são signos que tem tudo a ver com a alimentação (Câncer) e a apreciação de alguns prazeres como comer uma boa comida (Touro). Cintia também fala, que se o planejamento estiver ligado à internet ou aplicativos para celulares, é bom optar pela Lua ou Mercúrio em Aquário, signo que representa a tecnologia. Para negócios relacionados à moda, a Lua ou Vênus em Leão são boas opções. Têm-se uma reunião de negócios importante e as pessoas devem levar a sério o que for dito, a energia da Lua em Capricórnio facilita para que isto aconteça. Se o objetivo é dar uma festa com muita descontração a Lua em Virgem não é favorável, pois as pessoas devem ficar tímidas e inibidas. Para eventos como este, o melhor é escolher o dia em que a Lua estiver em Gêmeos ou Sagitário.

Conhecendo o mapa do planejamento ou das pessoas chaves envolvidas no processo, é possível escolher uma data e fazer o mapa do evento de acordo com o 
tipo de negócio e que melhor se adeque ao mapa do planejamento ou das pessoas envolvidas.

Apesar da escolha e do conhecimento do mapa do evento, não é possível garantir o sucesso do projeto, pois outros fatores influenciam para que isso aconteça, como esforço e dedicação empregada. E mesmo que seja possível escolher o momento ideal, existe o relativismo e o livre arbítrio que irão interferir nas escolhas que serão feitas no desenvolvimento do processo. Além disso, um negócio pode dar certo por determinado período e só porque não foi o tempo desejado, não quer dizer que não tenha dado certo.

A Astrologia é uma ferramenta que pode ajudar a entender e a vivenciar os momentos da melhor maneira possível. Seja para colher os resultados positivos ou para saber lidar com os períodos de tensão e crise. E nesse caso a Astrologia Eletiva (escolha do momento adequado para determinado empreendimento) pode ser uma grande aliada no mundo corporativo.

\subsection{Calendário do planejamento baseado na astrologia}

A astrologia tem relação direta com os ciclos da natureza, que eram observados para que o homem pudesse lidar melhor com os seus assuntos e a vida na Terra. Os antigos observavam os movimentos dos astros no céu e percebiam sua relação com os acontecimentos na Terra. O plantio e a colheita, por exemplo, sempre foram feitos de acordo com o céu, em especial as estações do ano - relacionadas à relação entre os movimentos da Terra e do Sol - e às fases da Lua - que acontecem pela relação entre os movimentos Sol-Lua-Terra. Até hoje isso ainda é levado em consideração por parte da população.

Pensando na Astrologia aplicada ao indivíduo, por exemplo, o mapa astral conta nossa história e nós contamos a história de nosso mapa. Pode ser sentido como "um símbolo vivo do universo inteiro, visto de um determinado lugar, num determinado instante" (RUDHYAR, 1991, p. 23).

Os ciclos astrológicos falam dos eventos coletivos e pelas observações astrológicas podemos fazer uma retrospectiva na história e contar o passado, podemos analisar o presente e prever o futuro.

Como conta o astrólogo Maurício Bernis (2007, p. 9), há correlações entre as posições dos astros e os eventos humanos, já que todos os mecanismos de funcionamento do universo obedecem a cíclicas naturais. O astrólogo ainda 
acrescenta que com base em inúmeras pesquisas e estatísticas sabemos que a Astrologia permite a análise desses ciclos. Assim, os ciclos celestes contam a história da vida terrestre.

\section{CRIAÇÃO DA CAMPANHA}

\subsection{Tema}

A ideia das peças propostas sobre a aparência do produto, utilizamos a manifestação minimalista, cujo seu objetivo é concentrar ao máximo a variedade em uma única imagem reduzida a si mesmo. As formas expostas nas camisas são potencializadas ao extremo, de modo a eliminar qualquer referência subjetiva, e ou, figurativa.

O padrão cromático para as peças, tem variações referente a cada signo e como ele se preocupa em orientar-se em comunidade. As cores estão de acordo com um estudo já feito para saber a relevância em que cada signo tem para cada pessoa, tornando isso uma proposta artística onde o minimalismo é a redução do conteúdo representativo de forma já visível, à mais simples expressão da mesma.

A linha criativa foi abordada no mundo da moda baseando-se na astrologia e segmentando-o de maneira única e alinhada com os seus propósitos e conceitos ressaltando nas peças fashions.

A temática de cada signo traduz o comportamento e posicionamento em que cada um tem na sociedade, visto que o ser humano não quer apenas ser notado, mas sim compreendido pela imagem que se é apresentada.

\subsection{Redação publicitária}

A Publicidade exerce um papel importante na sociedade como formadora de opinião, atuando em meios educacionais, jurídicos, religiosos, mudando conceitos, regras, interferindo diretamente ou indiretamente nos comportamentos tidos como corriqueiros na sociedade. Ela utiliza de vários aspectos estéticos para persuadir e cativar seu consumidor, desde usos de acontecimentos históricos, temas cotidianos e bordões na intenção de provocar novos sentimentos e sentidos ao comprador antes de sua aquisição final. A partir disso, surge a então a redação publicitária, cujo seu objetivo é fazer com que anúncios sejam entendidos por um conjunto, pois segundo (MARTINS, 2009, p.38.) "comunicar significa tornar comum, acessível a todos. [...]" 
A partir daí, entra todo o processo do redator publicitário, no qual tem a responsabilidade de conduzir as pesquisas e criar um conceito que irá orientar todo o processo de divulgação, seja ele em massa ou não. O redator publicitário também vai determinar a linguagem correta diante a seu público-alvo, para que o designer desenvolva matérias gráficas que serão utilizados dentro de uma campanha.

Em todo o processo de uma construção de marca e de sua expansão, a redação publicitária é uma das técnicas responsáveis para conceituar e contextualizar campanhas de divulgação sendo um dos pilares da publicidade. O redator publicitário não consiste apenas em uma produção de texto, mas abrange todo um processo criativo e essencial para as atividades na comunicação, sendo um elemento importante para o desenvolvimento de um trabalho mais amplo de todo o seu processo de divulgação em empresas e marcas. Segundo Figueredo:

"A condição fundamental ao sucesso de uma peça de comunicação é a existência de uma mensagem clara, uma afirmação sobre a marca ou o produto que desejamos fixar na mente dos cidadãos" (FIGUEREDO, 2005, p. 25).

\subsection{Direção de arte}

O diretor de arte é antes de tudo um profissional da criação no qual a sua função é idealizar anúncios para as mais diversas mídias. Ele pertence ao departamento de criação em uma agência que realiza um trabalho ao lado de um redator. Ambos dividem tarefas onde o redator reproduz textos e chamadas e o diretor de arte exerce a função de criar Layouts, sugerir alterações, acompanhar de perto a direção de fotografia, dirigir produções e por fim, orientar a equipe para um trabalho eficaz e coeso. Vale ressaltar que tanto o redator quanto o diretor, podem participar das duas funções dentro de uma agência, já que a partir de um briefing o diretor e o redator se reúnem com a equipe para um brainstorming. O brainstorming, ou tempestade de ideias, é um dos processos dos mais importes para um trabalho em equipe na comunicação. Este método foi idealizado no final dos anos 30 pelo publicitário e escritor Alex Faickney Osborn, que observou a necessidade em agências a discutir ideias e conceitos para formar uma opinião em conjunto a equipe, gerando ideias de maneira livre de obstáculos, críticas e ou julgamentos.

Para a construção de uma publicidade de sucesso, o diretor de arte faz uma análise da configuração visual de toda a campanha. $A$ análise no final de construção de ideia é rotineira na vida do diretor, visto que tudo tem que estar de acordo com a 
proposta já pré-estabelecida. Segundo Rafael Sampaio (1999, p. 232) "uma das principais funções da propaganda é criar, desenvolver, expandir, manter e até reciclar marcas" desse modo, entende-se que a função de uma direção de arte é nada mais que deixar todo o material compreensível e de acordo com tendências, gostos e singularidade de seu público. É imprescindível que o diretor de arte ande ao lado de um Designer gráfico, já que a peça criada tem que encurtar laços com o receptor da mensagem, ou seja, o consumidor.

Diante a toda uma concepção do que o diretor de arte tem como tarefa, utilizamos a linha de raciocínio da mesma forma. Os produtos criados para os signos foram se adequando conforme pesquisas de gostos e particularidades foram feitas. Foi utilizado softwares como Adobe Photoshop e llustrator onde ambas as ferramentas são caracterizadas como editores de imagens bidimensionais. As duas ferramentas são consideradas líderes no mercado dos editores de imagens digitais ou trabalhos de pré-impressão.

\section{CONSIDERAÇÕES FINAIS}

Em virtude dos fatos mencionados, a astrologia proporciona um conhecimento não só de si mesmo perante o mundo, mas de como ela de alguma forma rege tudo ao que está ao nosso redor, fazendo coligação com o planejamento de uma campanha publicitária.

Com o planejamento baseado na astrologia, podemos identificar em que momento estará mais propício para cada ação, assim, obtendo resultados mais concluintes, mas vale ressaltar que astrologia não é uma verdade, mas sim, uma possibilidade, pois todos estão sujeitos ao livre arbítrio, mesmo utilizando a astrologia como um norte.

A moda como vimos no presente trabalho, busca não apenas ser uma vestimenta, mas sim uma forma de representação de quem se é verdadeiramente, com isso, viu na astrologia uma forma de intensificar sua identidade, fazendo com que o consumidor se sinta representado, gerando uma identificação.

Assim, o trabalho viu por meio da atualidade a forte presença que a astrologia tem e viu a oportunidade de se inovar no setor publicitário, usando um meio de autoconhecimento para gerar ainda mais identificação com os seus consumidores. 


\section{REFERÊNCIAS}

BOBRICK, Benson. Escrito en el cielo: una história de la astrología. Buenos Aires:

El Ateneo, 2007.

CALDAS, Dario. Observatório de Sinais. Teoria e prática da pesquisa de tendências. Rio de Janeiro, Editora Senac, 2004.

CHEVALIER, Jean. GHEERBRANT, Alain. (1991) Dicionário de Símbolos - Mitos, sonhos, costumes, gestos, formas, figuras, cores, números. 5 . ed. Rio de Janeiro: José Olympio.

CHURCHILL, JR. G. A.; PETER, J. P. Marketing: Criando valor para os clientes. 2 ed. São Paulo: Saraiva, 2000.

DICIONÁRIO Brasileiro da Língua Portuguesa. São Paulo: Mirador Internacional, 1980

FEGHALLI, Marta. As engrenagens da moda. Rio de Janeiro, Editora Senac, 2001.

FLUSSER, Vilém. O mundo codificado. Por uma filosofia do design e da comunicação. São Paulo: Cosac Naify, 2007.

FREUD, Sigmund. Novas conferências sobre psicanálise. Imago, São Paulo, 1980.

GARCIA, Carol. MIRANDA, Ana Paula. Moda é Comunicação. São Paulo: Anhembi Morumbi, 2005.

GÉRAD, Pierre. Introdução ao Marketing. São Paulo, 1973.

GOMES, João. Gestalt do Objeto - Sistema de Leitura Visual da Forma. 2013. Disponível em: <https://graficovisual.files.wordpress.com /2013/11/gestalt-do-objetojoao-gomes.pdf >. Acesso em 27 de out. de 2018 às 15:10

HUTIN, Serge. História da astrologia. Lisboa: Edições 70, 1970

ISSUU. Redação Publicitária - Sedução pela palavra. 2016. Disponível em: < https://issuu.com/dhowglas/docs/livro_celso_figueiredo___reda___o_> Acesso em 25 de out. de 2018 às 20:32

JUNG, C. G. A natureza da psique . Vozes, Petrópolis, 1986.

A prática da psicoterapia. Vozes, Petrópolis, 1987.

. A psicologia da transferência. Vozes, Petrópolis, 1987

KOTLER, Philip. KELLER, Kevin. Administração de Marketing. 12ª Ed. São Paulo: Pearson Prentice Hall, 2006.

KOTLER, Philip. Administração de marketing: análise, planejamento, implementação e controle. $5^{\circ}$ ed. São Paulo: Atlas,1998. p.725. 
KOTLER, P.; ARMSTRONG, G. Princípios de Marketing. 12 ed. São Paulo: Pearson Prentice Hall, 2007.

KOTLER, P.; KELLER, K. L. Administração de Marketing. 12 ed. São Paulo: Pearson Prentice Hall, 2006.

LAS CASAS, A. L. Marketing: conceitos, exercícios, casos. 7 ed. 2. reimpr. São Paulo: Atlas, 2006.

LEHNERT, Gertrud. História da moda do século XX. Colónia: Könemann, 2001.

LUPETTI, LUÍS. Planejamento de Comunicação. Ed.Futura, São Paulo, 2000. P. 256.

MARSHALL, Peter. A astrologia no mundo. Rio de Janeiro: Nova Era, 2004.

MARTINS, Zeca. Redação Publicitária - A prática na prática. 3aㅗ ed. São Paulo: Atlas S.A 2013

MONTEIRO, Giovani Siqueira. O desenho como elemento gráfico na criação da roupa. Belém, 2002. (Trabalho Conclusão de Curso) Educação artística, habilitação Desenho, Universidade da Amazônia.

MORIN, Edgar; CASSÉ, Michel. Filhos do céu: entre vazio, luz e matéria. Rio de Janeiro: Bertrand Brasil, 2008.

PALOMINO, Érika. A moda. São Paulo: Publifolha, 2002.

PETROSSIAN, Lena. Do nascimento ao renascimento da Astrologia. In: MORIN, Edgar; et ali. O retorno dos astrólogos. Lisboa: Moraes, 1972, p. 15-27.

PLOTINO. Ennead II-3-1. Tradução de A.H. Amrstrong. Cambridge: Harvard University Press, 1996

PADRO, Cintia Blog. Astrologia eletiva e planejamento de negócios. 2014. Disponível em: <https://mapaeastral.com/2014/01/15/astrologia-eletiva-e-oplanejamento-de-negocios/>. Acesso em 28 de out. de 2018 às 18:46.

RAMOS, Rogério. Brainstorming. 2018. Disponível em: <

https://www.infoescola.com/administracao_/brainstorming/> Acesso em 03 de nov. de 2018 às 15:45.

REVISTA, Alceu. Da cultura visual à cultura material: o minimalismo como forma de expressão na sociedade de consumo. 2013. Disponível em <http://revistaalceu.com.puc-rio.br/media/alceu\%2031\%20pp\%20131-140.pdf>. Acesso em 03 de nov. de 2018 às 13:50.

SAMPAIO, Rafael. Propaganda de A a Z. 3ª edição - São Paulo: EditoraCampus, 2003.

SANTARELLI, Christiane Paula Godinho. O consumo da moda nas classes economicamente inferiores. São Paulo: USP, 2000. 
SHELDRAKE, Rupert; FOX, Matthew. A física dos anjos: uma visão científica e filosófica dos seres celestiais. São Paulo: Aleph, 2008.

STUCKRAD, Kocku von. História da astrologia: Da Antiguidade aos nossos dias. São Paulo: Globo, 2007

TOWNLEY, John. Ciclos astrológicos e períodos de crise. $2^{2}$ ed. São Paulo:

Pensamento, 1998.

VOGUE BRASIL. Susan Miller leva a astrologia para a moda em nova coleção. 2012. Disponível em: <http://revista.vogue.globo.com/moda/news/susan-miller-levaa-astrologia-para-a-moda-em-nova-colecao/>. Acesso em: 26 de Outubro de 2018 às 19:49. 